\title{
Alterações recentes da educação superior: limites e perspectivas para a universidade pública
}

\author{
Higher education recent changes: limits and perspectives for a public \\ university
}

\section{Alteraciones recientes de la enseñanza superior: límites y perspectivas para la universidad pública}

\author{
Eliane Cleide da Silva Czernisz ${ }^{1}$ \\ Universidade Estadual de Londrina, Professora no Departamento de Educação
}

\author{
Lorena Dominique Vilela Freiberger ${ }^{2}$ \\ Rede Básica da Prefeitura de Leópolis, Professora
}

\begin{abstract}
Resumo: Com este texto objetivou-se discutir a educação superior frente às recentes alterações da política educacional brasileira. Questiona-se: que características são assumidas pela educação superior no contexto das atuais políticas educacionais? Que limites e perspectivas estão postos para a universidade pública? A análise é desenvolvida tendo por base a abordagem materialista histórica, utilizando-se de discussão bibliográfica e análise de documentos. Entre os resultados, destaca-se que a educação superior passou por alterações significativas desde 1990 e que, assumindo a lógica operacional, ampliou a quantidade de vagas e de instituições, mantendo-se direcionada pelo desenvolvimento econômico. Finaliza ressaltando a importância do acompanhamento e da luta política em prol da garantia de uma educação superior de qualidade.
\end{abstract}

Palavras-chave: Política educacional. Educação superior. Universidade pública.

Abstract: The objective of this text is to discuss higher education before the recent changes in the Brazilian educational policy. It asks the following questions: Which characteristics are assumed by higher education in the current educational policies context? Which limits and perspectives are posed to the public university? The analysis is based on the historical materialism approach, using bibliographic discussion

\footnotetext{
Doutor em Educação pela Universidade Estadual Paulista Júlio de Mesquita Filho; Mestre em Educação pela Universidade Estadual de Maringá.

2 Graduada em Pedagogia pela Universidade Estadual do Norte do Paraná; Mestranda em Educação pela Universidade Estadual de Londrina.
} 
and documental analysis. Results showed that high per education has gone through significant changes since 1990, and that, assuming an operational logic, expanded the number of institutions and students, keeping the focus on economic development. It concludes by emphasizing the importance of monitoring and the political struggle for a higher education of quality.

Keywords: Educational policy. Higher education. Public university.

Resúmen: El texto objetiva discutir la enseñanza superior delante a las recientes alteraciones de la politica educativa brasileña. Cuestiona: ¿Qué características son asumidas por la enseñanza superior en el contexto de las actuales políticas educativas? ¿Qué límites y perspectivas están puestos para la universidad pública? El análisis se desarrolla tomando por base el abordaje materialista histórico, utilizando de discussión bibliográfica y el análisis de documentos. Entre los resultados, destaca que la enseñanza superior pasó por alteraciones significativas desde 1990, y que, asumiendo la lógica operacional, amplió la cantidad de vacantes y de instituciones, manteniéndose direccionada por el desarrollo económico. Finaliza, resaltando la importancia del acompañamiento y de la lucha política en favor de la garantía de una enseñanza superior de calidad.

Palabras clave: Política educativa. Enseñanza superior. Universidad pública.

\section{INTRODUÇÃO}

Neste texto, apresentamos uma reflexão teórica sobre a educação superior brasileira, com o objetivo de discuti-la a partir das recentes alterações da política educacional nos governos Fernando Henrique Cardoso, Luiz Inácio Lula da Silva, Dilma Vana Rousseff e Michel Temer. Partimos do entendimento de que temos presenciado, a partir de 1990, o desenvolvimento de uma lógica mercantil na educação, em sentido amplo, e na educação superior, de modo mais específico. Tal direcionamento traz novas características para a educação superior e redefine a universidade. Soma-se a isso o processo de expansão das universidades da rede federal no período dos governos de Luiz Inácio Lula da Silva (2003-2010), de ampliação institucional e redefinição políticopedagógica, na gestão de Dilma Vana Rousseff (2011-2015), e de claras intenções privatizantes, no governo de Michel Temer, a partir de 2015.

Tais fatos mostram uma sequência de encaminhamentos que nos leva a questionar: que características são assumidas pela educação superior no contexto 
das atuais políticas educacionais? Que limites e perspectivas estão postos para a universidade pública? Entendemos que a compreensão desse processo requer, além de uma análise dos acontecimentos atuais, também aqueles que mediaram o processo de desenvolvimento das políticas educacionais a partir dos anos 1990. Utilizamos para tal a abordagem materialista histórica, a fim de verificar, além dos aspectos históricos, a relação com as questões econômicas, sociais e políticas mais amplas e o embate de classes que têm norteado as políticas educacionais. De acordo com Frigotto (2006, p. 77), compreendemos que essa perspectiva de análise está relacionada a "[...] uma concepção de realidade, de mundo e de vida no seu conjunto.”

Para concretizar o que propomos, realizamos discussão bibliográfica visando a esclarecer o desenvolvimento da educação superior, as sugestões feitas por organismos internacionais e a ampliação da educação superior nos governos de Luiz Inácio Lula da Silva, Dilma Vana Rousseff e Michel Temer. Entendemos que tais aspectos contribuem para discutir a educação superior no período descrito, possibilitando desvelar as intencionalidades que permearam esse processo.

Também recorremos à análise de documentos governamentais e à legislação educacional, pois, com eles, teremos condições de compreender os encaminhamentos normativos que indicam o funcionamento da educação superior no contexto brasileiro, bem como as intenções para sua implementação. Nesse sentido, destacamos, entre os documentos analisados, o Plano Diretor da Reforma do Aparelho do Estado (PDRAE) (1995), o Plano de Desenvolvimento Educacional (PDE) (2007) e o Plano Nacional de Educação (PNE) (2001; 2014).

Utilizamos, ainda, documentos de organismos internacionais, como o Banco Mundial e a Unesco, por possibilitarem compreender as indicações e tendências projetadas para o desenvolvimento educacional e econômico no cenário mundial. A opção por tais organismos internacionais deve-se à atuação observada na área da educação, conforme discutiram Shiroma, Moraes e Evangelista (2000). A análise de documentos tem por base o estudo de Evangelista (2009), que contribui para discutir as intencionalidades do proposto nos documentos, sua historicidade e as relações que estabelecem ou não com as políticas em curso.

Desse modo, como ponto de partida, recuperamos elementos históricos dos anos 1990, momento em que a universidade explicita sua face competitiva, como forma de situar as propostas ocorridas na década para a educação superior, 
estabelecendo relação com as alterações do aparelho do Estado e com a redefinição da economia, ações cuja concretização verificamos nos dias atuais.

Numa segunda etapa, apresentamos as propostas governamentais para o desenvolvimento da educação superior, situando, como característica marcante, a expansão da rede federal vinculada às perspectivas de desenvolvimento econômico regional. Esse processo permitiu a criação de novas universidades, a ampliação de instituições e a recomposição de outras já existentes. Para finalizar, apresentamos algumas indicações sobre os impasses e as perspectivas para a educação superior no atual momento no Brasil.

\section{A POLÍTICA EDUCACIONAL BRASILEIRA E A EDUCAÇÃO SUPERIOR NA DÉCADA DE 1990}

A década de 1990 é considerada importante para o estudo das políticas educacionais desenvolvidas no cenário brasileiro, principalmente por ser período posterior a um processo ditatorial em que a esperança de construção de uma sociedade mais justa e democrática foi fortalecida com a promulgação da Constituição Brasileira de 1988. Trata-se também de um momento em que estiveram presentes o revigoramento das forças sociais e a implementação do neoliberalismo.

Conforme comentado por Frigotto (2011, p. 140), na década de 1990, no Governo de Fernando Henrique Cardoso, houve opção "[...] pela modernização e dependência mediante um projeto ortodoxo de caráter monetarista e financista/ rentista." Nesse projeto, pelo que pudemos depreender do autor, não havia espaço para a face social do Estado. Isso porque estava em curso um desenvolvimento econômico sintonizado com os ideais neoliberais cujas reinvindicações de eficiência, eficácia e impressão de uma lógica empresarial passaram a vigorar nos serviços públicos.

Tais ideais, em nosso entendimento, evidenciam as intenções das tratativas firmadas no Consenso de Washington, realizado em fins dos anos 1980, acordo que elencou condicionantes para que os países periféricos alcançassem desenvolvimento econômico e não deixassem de pagar a dívida externa, um assunto que pode ser verificado em Ugá (2004). Percebemos, com base na autora, que tais ideias resultaram da crise econômica de 1970. O ideário daí originado trouxe para o Brasil o intuito de uma reforma do aparelho do Estado que, conforme Sguissardi e Silva Júnior (2009, p. 119), tornou-se “[...] Estado Gestor que se desvencilha de muitas de suas 
funções específicas tradicionais, mormente no setor de serviços, e as transfere total ou parcialmente para o mercado, entre elas situando-se a educação superior."

Com o Plano Diretor da Reforma do Aparelho do Estado (PDRAE) (BRASIL, 1995), realizado no Governo de Fernando Henrique Cardoso, em 1995, o aparelho do Estado passou a ter quatro setores de atividades: núcleo estratégico; atividades exclusivas; serviços não exclusivos; e produção de bens e serviços para o mercado. Nessa nova organização, a educação compôs o setor de serviços não exclusivos, pelo entendimento de que as ações educacionais podem também ser desenvolvidas por organizações públicas, porém não estatais ou até mesmo privadas. De acordo com o Plano Diretor, “[...] São exemplos desse setor: as universidades, os hospitais, os centros de pesquisa e os museus." (BRASIL, 1995, p. 42-43).

Nas análises desenvolvidas por Chauí (2003) sobre a universidade, a autora entende que, com o processo de reforma do aparelho do Estado, a educação passou a ser considerada um serviço que pode ser privatizado. Para ela, a universidade perde a característica de instituição social e passa a ser regida como organização. A autora explica:

A instituição social aspira à universalidade. A organização sabe que sua eficácia e seu sucesso dependem de sua particularidade. Isso significa que a instituição tem a sociedade como seu princípio e sua referência normativa e valorativa, enquanto a organização tem apenas a si mesma como referência, num processo de competição com outras que fixaram os mesmos objetivos particulares. Em outras palavras, a instituição se percebe inserida na divisão social e política e busca redefinir uma universalidade (ou imaginária ou desejável) que lhe permita responder às contradições impostas pela divisão. Ao contrário, a organização pretende gerir seu espaço e tempo particulares, aceitando como dado bruto sua inserção num dos pólos da divisão social, e seu alvo não é responder às contradições e sim vencer a competição com seus supostos iguais. (CHAUí, 2003, p. 69).

Pelo que se verifica na discussão de Chauí, no Brasil, a universidade passa de instituição, cuja especificidade é formar quadros para os setores públicos, professores, para a educação básica e superior e bacharéis para uma organização que visa a atingir resultados. Percebemos haver uma diferença bastante significativa sobre o papel das instituições de educação superior que, antes do Plano Diretor, organizavam-se para atender às necessidades sociais, voltando-se à produção do conhecimento e, depois, passaram a buscar resultados que fossem expressivos para o mercado.

Além de ser preciso considerar que, no período em questão, o capitalismo se organiza em busca da produção de tecnologias, de produtos, de inovação, importante 
também destacar que o conhecimento se torna uma vantagem competitiva significativa, passando a ter valor reconhecido, como podemos depreender das análises de Harvey (1994). Pela discussão de Chaú (2003), inferimos que as reformulações do sentido da universidade exigem hoje que tais instituições produzam resultados. Ademais, observamos que a análise do tipo de universidade que temos, assim como do papel a ser exercido por ela, estão relacionados com o tempo histórico. Chauí afirma que, nos anos 1970, a universidade foi "funcional", pois “[...] foi o prêmio de consolação que a ditadura ofereceu à sua base de sustentação político-ideológica, isto é, à classe média despojada de poder. A ela, foram prometidos prestígio e ascensão social por meio do diploma universitário." (CHAUÍ, 2003, p. 70). O objetivo dessa universidade, conforme Chaú, foi a rápida formação de mão de obra adaptada ao mercado, um aspecto presente ainda nos dias atuais.

Nos anos 1990, a universidade, segundo Chauí, passa a corresponder ao neoliberalismo, transforma-se em instituição operacional e, voltando-se para si mesma, estabelece regras de gestão e arbitragem de contratos. Para a autora, a universidade transforma a docência:

Nela a docência é entendida como transmissão rápida de conhecimentos, consignados em manuais de fácil leitura para os estudantes, de preferência ricos em ilustrações com duplicata em CDs. O recrutamento de professores é feito sem levar em consideração se dominam ou não o campo de conhecimentos de sua disciplina e as relações entre ela e outras afins - o professor é contratado ou por ser um pesquisador promissor que se dedica a algo muito especializado, ou porque, não tendo vocação para pesquisa, aceita ser escorchado e arrochado por contratos de trabalho temporários e precários, ou melhor "flexíveis". A docência é pensada como habilitação rápida para graduados, que precisam entrar rapidamente num mercado de trabalho do qual serão expulsos em poucos anos, pois se tornam, em pouco tempo, jovens obsoletos e descartáveis, ou como correia de transmissão entre pesquisadores e treino para novos pesquisadores. Transmissão e adestramento. Desapareceu, portanto, a marca essencial da docência: a formação. (CHAUí, 2003, p. 71).

Lembramos que o aligeiramento da formação e sua transformação em treinamento tornou-se uma característica do perfil docente desenvolvido no contexto de reforma do Estado e de influências externas. Melo (2006) comenta as interferências do Banco Mundial na redefinição do ensino superior. Entendemos, a partir dessa autora, que as alterações promovidas nas políticas para a educação superior foram influenciadas por organismos internacionais que consideram a estagnação do 
desenvolvimento econômico dos países periféricos resultado da ineficiência das instituições formadoras que deveriam estar voltadas

[...] à transformação do conhecimento em bens e serviços, no sentido de realizar um sistema nacional de inovação, com suas universidades sendo responsáveis também por estimular e realizar parcerias tanto com a comunidade científica internacional quanto com o setor privado; responsáveis igualmente por treinar cérebros e recursos humanos, bem como por instituir um sistema de acompanhamento e avaliação de seus sistemas, estimulando a competição e proporcionando a comercialização de seus produtos. (MELO, 2006, p. 130).

A preocupação com o conhecimento explicitada no excerto pode ser reforçada com os argumentos de Melo (2006) nos três documentos mencionados a seguir, que expressam interesse pela educação superior e que, de algum modo, trazem sugestões para a educação e para a formação. O primeiro é o Informe sobre el desarrollo mundial: El conocimiento al servicio del desarrollo - 1998-1999, produção do Banco Mundial, cuja preocupação central é com o conhecimento dos países pobres, aspecto importante, já que se verifica no documento que o que é entendido como conhecimento são informações produzidas nos países de economias centrais. No Informe, o conhecimento é tratado com um sentido utilitário para ser consumido nos países periféricos.

Destacamos como segundo Documento, conforme Leher e Barreto (2008, p. 425), Educação Superior nos Países em Desenvolvimento: Perigos e Promessas, editado em conjunto pelo Banco Mundial e pela Unesco, que, novamente, menciona o acesso aos conhecimentos já produzidos nos países mais desenvolvidos, assim como o aumento do número de alunos. O terceiro Documento, a Declaração de Paris - Declaração Mundial sobre Educação Superior no Século XXI: Visão e Ação (UNESCO, 1998), gestada no bojo das mudanças econômicas e políticas, afirma o papel das instituições de ensino superior no que diz respeito ao desenvolvimento econômico e à ampliação da chamada sociedade do conhecimento. Essa indicação demonstra o lugar ocupado pela educação no atual contexto e principalmente seu teor utilitarista.

Tais documentos divulgaram ideias e sugestões para que a educação superior fosse reformada. Entre as alterações ocorridas, destacamos o Processo de Bolonha que, apesar de se constituir como caso europeu, representa tendência reformista, e, como comentaram Mello e Dias (2011), esse processo envolveu desde os regimes jurídicos das instituições até a carreira docente e as formas de financiamento 
das instituições. Os autores afirmam que o Processo de Bolonha “[...] não passaria de um enquadramento funcional do mundo acadêmico às novas exigências de eficácia e competitividade associadas às características presentes do atual sistema econômico mundial." (MELLO; DIAS, 2011, p. 417).

Para Silva Junior (2002), o alinhamento da educação superior às necessidades econômicas ocorridas no Governo de Fernando Henrique Cardoso promoveu a redefinição das instituições de educação superior, voltando a formação para o atendimento do mercado. Tratou-se de alterações institucionais profundas em meio a um “[...] intenso processo mundial de reformas.” (SILVA JUNIOR, 2002, p. 69).

Shiroma, Moraes e Evangelista (2000, p. 94) citam, como fruto desse Governo, a complementação de legislação que contribuiu para reforma, alteração da forma de seleção e ingresso em cursos de graduação, a flexibilização de cursos que poderiam estar voltados a "[...] diferentes áreas de conhecimento [...] ou cursos sequenciais por campos de saber, de diferentes níveis de abrangência", e a possibilidade de "[...] credenciamento de cinco tipos de IES - universidades, centro de educação superior, institutos, faculdades e escolas superiores $[\ldots]$ ”

Com base na análise das autoras, podemos perceber que há um controle exercido pelo Estado por meio da avaliação dos cursos e das instituições de educação superior, característica que permanece vigente nos dias atuais e que tem promovido um ranqueamento das instituições superiores de ensino tanto na graduação quanto na pós-graduação.

Entendemos que tais encaminhamentos não destoam daqueles elencados como metas do PNE, ${ }^{3}$ Lei n. 10172/2001, elaborado e aprovado no Governo Fernando Henrique Cardoso. O PNE em questão reconhece a necessidade de se ampliar o alcance da educação superior incluindo, entre metas e objetivos, a abertura para a educação a distância, a diversificação do sistema superior de ensino e da oferta de ensino, a ampliação do número de mestres e doutores, o estímulo ao desenvolvimento da pósgraduação, o reforço à avaliação institucional e à qualidade do ensino, entre outros.

Numa tentativa de síntese desse amplo período, cujos dados aqui reconhecemos são apenas ilustrativos, reforçamos que a educação superior se desenvolveu amalgamada às intencionalidades de desenvolvimento econômico

3 Observamos que o PNE, aprovado naquele Governo, substituiu e desconsiderou o PNE proposto pela sociedade civil brasileira e organizado por ela, como alternativa elaborada nas edições dos Congressos Nacionais de Educação (CONEDs). Esse assunto é discutido por Bollmann (2010). 
da sociedade brasileira e das formas de gestão implementadas pelas alterações do aparelho do Estado. Como veremos adiante, tais acontecimentos não foram dissipados da política educacional para a educação superior nos governos seguintes, ao contrário, foram aprofundados.

\section{A EDUCAÇÃO SUPERIOR A PARTIR DOS ANOS 2000}

No Governo de Luiz Inácio Lula da Silva havia claras expectativas por parte da classe trabalhadora de que os encaminhamentos em prol das políticas sociais e da educação fossem diferentes do que se preconizava anteriormente no cenário nacional. Nas análises de Frigotto (2011), esse Governo, iniciado no ano 2003, é um marco conjuntural importante pela definição de encaminhamentos que prosseguiriam no País. O autor afirma que a opção foi pela

[...] retomada, ainda que de forma problemática, da agenda do desenvolvimento; alteração substantiva da política externa e da postura perante as privatizações; recuperação, mesmo que relativa, do Estado na sua face social; diminuição do desemprego aberto, mesmo que tanto os dados quanto o conceito de emprego possam ser questionados; aumento real do salário mínimo (ainda que permaneça mínimo); relação distinta com os movimentos sociais, não mais demonizados nem tomados como caso de polícia; e ampliação intensa de políticas e programas direcionados à grande massa não organizada que vivia abaixo da linha da pobreza ou num nível elementar de sobrevivência e consumo. (FRIGOTTO, 2011, p. 240).

As análises de Frigotto permitem compreender que tais encaminhamentos, nas políticas sociais, não alteraram a estrutura social brasileira. Isso porque houve continuidade na aposta do desenvolvimento e continuidade à política macroeconômica. Para Frigotto (2011, p. 242), o que se vem observando atualmente no século XXI, na educação, teve o reforço de encaminhamentos presentes na década de 1990, sendo destacadas as parcerias público-privadas e a dualidade educacional que, segundo o autor, abrangem "[...] desde o conteúdo do conhecimento até os métodos de sua produção ou socialização."

Entendemos que a aproximação entre o projeto de desenvolvimento econômico e o da educação ocorreu por meio da aprovação do PDE, no ano 2007. O PDE, como informou Saviani (2007), foi lançado pelo Ministério da Educação no mesmo período em que era lançado o Plano de Aceleração do Crescimento (PAC). 
Para Saviani (2007, p. 1233), o PDE tem a forma de um programa "guarda-chuva", que "[...] abriga praticamente todos os programas em desenvolvimento pelo MEC." Conforme explica:

\begin{abstract}
No que se refere à educação superior, o Plano inscreve cinco ações: "FIES-PROUNI", que pretende facilitar o acesso ao crédito educativo e estender o prazo de ressarcimento, além de permitir o parcelamento de débitos fiscais e previdenciários às instituições que aderirem ao PROUNI; "Pós-doutorado", destinado a reter no país pessoal qualificado em nível de doutorado, evitando a chamada "fuga de cérebros"; "Professor Equivalente", que visa facilitar a contratação de professores para as universidades federais; "Educação Superior", cuja meta é duplicar, em dez anos, o número de vagas nas universidades federais; e o "Programa Incluir: Acessibilidade na Educação Superior", que visa ampliar o acesso de pessoas portadoras de deficiências a todos os espaços e atividades das instituições federais de ensino superior. (SAVIANI, 2007, p. 1236).
\end{abstract}

Dois aspectos chamam atenção no excerto em tela. Primeiro, verificamos que está em curso, desde a década de 1990, uma ênfase na titulação docente, para qualificar os quadros universitários. Como segunda questão e em caminho contrário ao reforço da permanência do corpo docente nas universidades, já que, para isso, entendemos, deveria ocorrer concurso, há indicações da flexibilização da contratação de docentes para as instituições federais de ensino. Esse é um elemento importante, pois permite perceber que, se por um lado os docentes estão sendo fortemente conclamados à capacitação, por outro, concomitantemente, outros docentes têm sido contratados em situação precária. O que iguala os dois grupos em destaque são as condições de trabalho a que se submetem, como podemos depreender das análises de Shiroma, Moraes e Evangelista (2000), que, especificamente, apontam a sobrecarga didática e as exigências de produção, ambas sob os auspícios da avaliação institucional. Nesse sentido, cumpre-se o que Chauí (2003) apontava como característica da universidade: aquela voltada a resultados e, em nosso entendimento, sem que sejam questionadas as condições em que estes ocorrem.

Vinculado ao PDE, em 2007, no Governo de Luiz Inácio Lula da Silva, por meio do Decreto n. 6.096, de 24 de abril, foi instituído o Programa de Apoio a Planos de Reestruturação e Expansão das Universidades Federais (REUNI), e, para tanto, o Governo destinou recursos às universidades que apresentassem um plano de reestruturação. 
Com o REUNI, o governo federal adotou uma série de medidas para retomar o crescimento do ensino superior público, criando condições para a expansão física, acadêmica e pedagógica da rede federal de educação superior. Os efeitos da iniciativa podem ser percebidos pelos expressivos números da expansão que transparecem na implantação de novas universidades, nos novos campi universitários e no aumento no número de matrículas. (BRASIL, 2014, p. 31).

Em que pesem as expectativas com a aprovação do REUNI, é preciso verificar como esse Programa está relacionado à sustentação do crescimento econômico, e algumas questões pontuadas por Frigotto (2011) são importantes para a reflexão. Segundo o autor:

O REUNI, por sua vez, representa uma inversão substantiva de recursos de custeio para projetos e programas, quase duplicando as vagas e sendo aplaudida fortemente pelo Manifesto dos Reitores das Universidades Públicas durante o atual governo. Em contrapartida, estabelece a desestruturação da carreira docente, conquistada duramente, aumenta o trabalho precário e, sobretudo, impõe uma brutal e, em muitos casos, insuportável intensificação da carga de trabalho. Além disso, especialmente pelo crescimento do enclave da educação à distância, em alguns casos com a defesa de sua crescente expansão em substituição ao ensino superior presencial, produz-se mais uma forma de dualidade. $\mathrm{O}$ fetiche da tecnologia opera aqui como argumento ideológico. (FRIGOTTO, 2011, p. 247).

As análises de Ferreira e Oliveira (2016) evidenciam a opção por um projeto de desenvolvimento econômico e social, nos governos Luiz Inácio Lula da Silva e Dilma Vana Rousseff, influenciando as políticas para a educação superior, com destaque para as universidades federais, dado que confirma indicações tanto de Saviani (2007) quanto de Frigotto (2011). Para Ferreira e Oliveira (2016, p. 18-19),

[...] as universidades mantidas pelo governo federal foram induzidas a assumir papel estratégico no projeto de desenvolvimento e a educação superior foi incluída numa perspectiva sistêmica de formação e geração de conhecimentos e inovações a fim de agregar e gerar mais valor aos processos de produção e prestação de serviços, o que incluiu alterações nas políticas, no financiamento, nas ações e nas estratégias da área de ciência, tecnologia e inovação.

Percebemos, então, um reforço ao sentido econômico e à combinação realizada na expansão das universidades federais como suporte, tanto na formação de mão de obra, quanto no desenvolvimento do conhecimento de interesse do mercado, 
o conhecimento que pode trazer vantagens competitivas como a produção de ciência, tecnologia e inovação.

Pela discussão de Ferreira e Oliveira (2016), é possível compreender que é nesse sentido que se realiza a expansão das universidades federais ocorrida no Governo Luiz Inácio Lula da Silva. Ferreira e Oliveira (2016) destacam 14 novas universidades:

Universidade Tecnológica Federal do Paraná (UTFPR), Universidade Federal dos Vales do Jequitinhonha e Mucuri (UFVJM), Universidade Federal Rural do Semi-Árido (UFRSA), Universidade Federal do Triângulo Mineiro (UFTM), Universidade Federal de Alfenas (Unifal), Universidade Federal Ciências da Saúde de Porto Alegre (UFCSPA), Universidade Federal do Recôncavo da Bahia (UFRB), Universidade Federal da Grande Dourados (UFGD), Universidade Federal do Oeste do Pará (Ufopa), Universidade Federal do ABC (UFABC), Universidade Federal Fronteira Sul (UFFS), Universidade Federal de Integração Latino-americana (Unila), Universidade de Integração Internacional da Lusofonia Afro-Brasileira (Unilab) e Universidade Federal do Pampa (Unipampa).

Os autores comentam que as "[...] seis primeiras universidades eram instituições que foram transformadas em universidades federais." (FERREIRA; OLIVEIRA, 2016, p. 37).

Se a quantidade de universidades federais é expressiva, quando verificamos os números de matrícula na educação superior, no Governo de Luiz Inácio Lula da Silva, entrando na gestão de Dilma Vana Rousseff, é perceptível o aumento do número de vagas e de inserção dos alunos. Segundo Ferreira e Oliveira (2016, p. 29), no ano “[...] 2003, o número de matrículas (presenciais e a distância) nos cursos de graduação nas universidades federais somava 544.251 e, em 2013, passou para 1.015.868.” É preciso observar, também, que as "novas" instituições, como ressaltaram os autores, “[...] passaram a diversificar-se em relação à sua identidade, organização e gestão acadêmica [...]" (FERREIRA; OLIVEIRA, 2016, p. 43). Inferimos que a alteração na natureza institucional traz também mudanças nos papéis desenvolvidos pelo quadro funcional da instituição.

Além de se considerar a importância do crescimento numérico das instituições de educação superior, há também que ser ressaltado, conforme Ferreira e Oliveira (2016, p. 19), que a universidade deixa de ter desenvolvimento institucional autônomo, tornando-se uma instituição estatal. Isso porque, segundo os autores, o 
Estado passa a induzir o crescimento e a competitividade do País e, nesse sentido, "[...] a universidade assumiu ainda mais a perspectiva de formar profissionais com competências apropriadas para o mundo do trabalho e com a capacidade de produzir conhecimentos, tecnologias e inovações ajustados às demandas produtivas."

Pela discussão dos autores, concluímos que, com a expansão, houve uma ampliação do alcance das universidades, via criação de campi em regiões que não contavam com universidades. Ressaltamos a importância de tal ampliação como forma de oportunizar educação superior para jovens, a quem o acesso à universidade ainda não foi possibilitado. Desse modo, tais instituições favoreceram tanto a inclusão social quanto a concretização do projeto de desenvolvimento regional, e como destacaram Ferreira e Oliveira (2016, p. 47):

As discussões sobre as finalidades da universidade, consoantes com o projeto de desenvolvimento proposto nas duas últimas décadas, principalmente nos governos Lula da Silva e Dilma Rousseff, vêm implicando a afirmação do modelo multicampi, na busca de inovações e de novos padrões de gestão universitária, visando a uma efetiva contribuição para o crescimento econômico e para a competitividade do país, aliada à redução das desigualdades sociais.

Segundo Ferreira e Oliveira (2016), no Governo Dilma houve continuidade da política de expansão da educação superior, ${ }^{4}$ com a criação da Universidade Federal do Sul da Bahia (UFSB), e transformação de outras instituições em universidades como Universidade Federal do Sul e Sudoeste do Pará (Unifesspa), Universidade Federal do Oeste da Bahia (UFOB) e Universidade Federal do Cariri (UFCA).

As notas estatísticas do Censo da Educação Superior do INEP (2014, p. 5) destacam o aumento da quantidade de matrículas na rede federal, indicando que $90 \%$ das matrículas da rede federal se concentravam nas universidades, sendo que no período de 2003 a 2014 houve aumento de 102,2\% no número de matrículas. Ressaltamos que, em relação às matrículas, o PNE, Lei n. 13.005/2014, aprovado para o período de 2014 a 2024, prevê na meta 12 não somente a ampliação da participação de jovens entre 18 e 24 anos na educação superior, mas também o estímulo à reestruturação e expansão de instituições de educação de ensino superior estaduais e municipais. Também vislumbra a melhoria da qualidade da educação superior, a ampliação da

\footnotetext{
4 Os autores destacaram, neste governo em específico, a criação, no ano de 2011, do Programa Ciência sem Fronteiras e da Lei de Cotas para as Universidades Federais, no ano de 2012.
} 
formação de mestres e doutores, a atuação regional, a elevação de taxa de conclusão dos cursos de graduação e a avaliação institucional.

A análise empreendida até o momento reforça alguns argumentos, como a conquista de vagas para a educação superior a partir da criação e reestruturação das universidades federais. Verificamos que a existência de novas instituições e novas vagas em regiões onde ainda não havia universidades é um aspecto importante para viabilizar a democratização do acesso à educação superior. Porém, também consideramos que a reestruturação ocorreu combinada com as necessidades de desenvolvimento econômico, secundarizando os problemas decorrentes, como as condições de funcionamento institucional, a precarização do trabalho docente e, atualmente, o corte de investimentos no setor público, aspectos que afetam as condições de permanência e a qualidade da educação superior.

Percebemos, então, que entramos em um período regressivo no ano 2015, quando Michel Temer assumiu a presidência, num processo possibilitado pelo impeachment da presidente Dilma Vana Rousseff, e bastante questionado por autoridades e estudiosos brasileiros e internacionais, momento a partir do qual entendemos que o Brasil passa a ter novos direcionamentos políticos que revigoram intentos neoliberais. De acordo com Mancebo (2017, p. 6), a base tomada para direcionamento governamental tem por orientação o Documento Uma ponte para o futuro (2015), segundo o qual, como explicou a autora, o Brasil gasta “" [...] muito com políticas públicas, fazendo-se necessária a construção de um equilíbrio fiscal por meio de cortes dos gastos públicos." Compreendemos que o encaminhamento tomado, e aqui concordamos com Mancebo, é o de aprofundamento do Estado mínimo e de perdas de direitos conquistados ao longo da histórica luta da população brasileira. Entre as mais emblemáticas, destacamos a perda de direitos trabalhistas resultado da reforma da previdência e da reforma trabalhista, assim como os cortes em investimentos públicos pela Emenda Constitucional n. 95/2016, pelo período de 20 anos.

A educação superior no Governo de Temer vem sofrendo as consequências de um direcionamento que atua na linha de corte, que se vincula a ações tomadas nos dias atuais e a outras que remontam a períodos anteriores em que a noção do dispêndio do setor público e da ineficiência da prestação de tais serviços imperava. Dados a respeito desses aspectos são visíveis nos encaminhamentos e críticas do referido Governo, entre as quais destacamos algumas comentadas pela Confederação Nacional dos Trabalhadores em Educação (CNTE) (2016), ao noticiar o projeto Uma ponte para 
o futuro: o congelamento dos gastos públicos, processo de privatização da educação superior, retração em investimentos para expansão da educação superior, proposição de alterações significativas na carreira e, acrescentamos, ataque à autonomia universitária.

No entendimento de Melo e Sousa (2017), os pressupostos da ponte para o futuro explicitam a volta dos interesses privatistas, da ênfase na competição e no mercado. Para nós, esse direcionamento afeta, de forma geral, todas as políticas sociais, e, no caso da educação superior, ressaltamos o que dizem os autores:

Na linha da desestabilização da garantia do direito à educação e de "contenção" de gastos ao ajuste financeiro seguiu-se a publicação, pelo Ministério da Educação, da Portaria Normativa $\mathrm{n}^{\mathrm{o}}$. 20, de outubro de 2016, que regulamenta a necessidade das Instituições de Ensino Superior reduzirem o seu quantitativo de oferta de vagas, marcando assim o desmonte previsto para a educação superior tornando-a um campo fértil para atuação dos barões do ensino nesse nível. (MELO; SOUSA; 2017, p. 33).

Para nós, o excerto traz indicações das perdas sociais no encaminhamento do Governo de Michel Temer e mostra o aprofundamento do direcionamento de um projeto governamental e de país voltado ao atendimento de interesses econômicos, um período de retrocesso que será necessário reverter no processo de lutas em prol de direitos sociais que havíamos conquistado.

\section{ALGUMAS CONSIDERAÇÕES}

Desenvolvemos este texto com o objetivo de discutir a educação superior a partir das recentes alterações da política educacional brasileira. De modo específico, os dados apresentados não esgotam as características assumidas pela educação superior nos diferentes governos. Do que nos predispomos a discorrer, verificamos ter ocorrido mudanças da universidade que, como organização, entendemos que continua atendendo aos interesses capitalistas.

Não podemos negar a ocorrência de um aumento do número de instituições de educação superior e do número de matriculados nos governos de Luiz Inácio Lula da Silva e Dilma Vana Rousseff, aspecto que consideramos um avanço na perspectiva da defesa das políticas públicas educacionais. Destacamos o importante papel da universidade enquanto espaço formativo possibilitado com a ampliação de instituições, cursos, vagas e contratação de docentes. A educação superior chegou a locais onde não 
havia universidades, e isso possibilitou a ampliação de vagas para muitos brasileiros. Não podemos, portanto, desconsiderar a importância disso no âmbito do direito à educação, aspecto que também expressa a participação dos segmentos representativos da educação em defesa do direito à educação e da ampliação de vagas na educação superior.

Entendemos que tal resultado se deve a reivindicações que se constituíram metas no PNE, vigente a partir de 2014, mas também se vinculam às necessidades de formação de mão de obra como suporte para o desenvolvimento econômico brasileiro. A ampliação do número de instituições de educação superior foi acompanhada de significativas alterações também no trabalho docente, cuja marca mais expressiva pode ser percebida pela precarização. No nosso entendimento, essas características compõem a lógica a ser seguida pela universidade operacional que funciona sob orientações dos pressupostos do mercado.

Consideramos que pensar a universidade hoje exige fazê-lo num sentido mais amplo das conquistas e retrocessos que temos vivido no cenário educacional brasileiro e, em específico, no que concerne à educação superior. Também exige pensá-la no horizonte social e político que se desenha com as decisões que vêm sendo encaminhadas pelos representantes políticos. Nossa responsabilidade é discutir a questão, propondo medidas para um justo e digno exercício da docência universitária, sendo reconhecidos pelo importante papel que desempenhamos. É, ainda, dever nosso não desistir da luta política para que o direito à educação e à educação superior de qualidade seja ampliado.

\section{REFERÊNCIAS}

BRASIL. Plano Diretor da Reforma do Aparelho do Estado. Brasília: MARE, 1995.

BRASIL. Lei n. 10.172/2001, de 09 de janeiro de 2001. Aprova o Plano Nacional de Educação e dá outras providências. Diário Oficial da União, Brasília, DF: República Federativa do Brasil, 2001. Disponível em: <http://www.planalto.gov.br/ccivil_03/leis/leis_2001/110172.htm>.Acesso em: 10 out. 2016.

BRASIL. Decreto n. 6.096, de 24 de abril de 2007. Institui o Programa de Apoio a Planos de Reestruturação e Expansão das Universidades Federais - REUNI. Diário Oficial da União, Brasília, DF: República Federativa do Brasil, 2007. Disponível em: <http://www.planalto.gov.br/ccivil_03/_ato2007-2010/2007/decreto/d6096. htm>. Acesso em: 04 ago. 2016. 
BRASIL. Lei n. 13005 de 25 de junho de 2014. Aprova o Plano Nacional de Educação - PNE e dá outras providências. Diário Oficial da União, Brasília, DF: República Federativa do Brasil, 2014. Disponível em: <http://www2.camara.leg.br/legin/ fed/lei/2014/lei-13005-25-junho-2014-778970-publicacaooriginal-144468-pl.html>. Acesso em: 02 ago. 2016.

BRASIL. Ministério da Educação. A democratização e expansão da educação superior no país 2003 - 2014. Portal do MEC, 2014. Disponível em: <http://portal. mec.gov.br/index.php?option=com_docman\&view=download\&alias=16762-balanco-social-sesu-2003-2014\&Itemid=30192> . Acesso em: 08 fev. 2016.

BRASIL. Ministério da Educação. Instituto Nacional de Estudos e Pesquisas Educacionais Anísio Teixeira. Notas Estatísticas. Censo da Educação Superior. Brasília, DF, 2014. Disponível em: <http://download.inep.gov.br/educacao_superior/censo_ superior/documentos/2015/notas_sobre_o_censo_da_educacao_superior_2014.pdf $>$. Acesso em: 19 out. 2016.

BANCO MUNDIAL. Informe sobre el desarrollo mundial: El conocimiento al servicio del desarrollo - Resumen. Washington, 1998-1999.

BOLMANN, M. G. Revendo o Plano Nacional de Educação: proposta da sociedade brasileira. Educação e Sociedade, Campinas, v. 31, n. 112, p. 657-676, jul./ set. 2010. Disponível em: <http://www.scielo.br/scielo.php?script=sci_arttext\&pid $=$ S0101-73302010000300002>. Acesso em: 22 set. 2016.

CHAUÍ, M. Universidade: Organização ou Instituição Social? In: UNESCO. A Universidade na Encruzilhada. Seminário Universidade: Por que e como reformar? Brasília: Unesco, MEC, 2003. p. 67-76.

CONFEDERAÇÃO NACIONAL DOS TRABALHADORES EM EDUCAÇÃO. Educação em Risco. Jornal Mural da Confederação Nacional dos Trabalhadores em Educação, maio 2016.

EVANGELISTA, O. Apontamentos para o trabalho com documentos de política educacional. In: COLÓQUIO A PESQUISA EM TRABALHO, EDUCAÇÃO E POLÍTICAS EDUCACIONAIS, 1., 2009, Belém. Anais... Belém: UFPA, 2009. p. $1-16$.

FERREIRA, S.; OLIVEIRA, J. F. Expansão, interiorização e alterações nas universidades federais no contexto do desenvolvimento. In: FERREIRA, S.; OLIVEIRA, J. F. (Org.). Universidades Públicas: mudanças, tensões e perspectivas. Campinas: Mercado das Letras, 2016. p. 17-56. 
FRIGOTTO, G. Os circuitos da história e o balanço da educação no Brasil na primeira década do século XXI. Revista Brasileira de Educação, v. 16, n. 46, p. 235-274, jan./abr. 2011. Disponível em: <http:/www.scielo.br/pdf/rbedu/v16n46/ v16n46a13>. Acesso em: 15 nov. 2015.

FRIGOTTO, G. O enfoque da dialética materialista histórica na pesquisa educacional. In: FAZENDA, I. (Org.) Metodologia da Pesquisa Educacional. São Paulo: Cortez, 2006. p. 69-90.

HARVEY, D. Condição pós-moderna: uma pesquisa sobre as origens da mudança cultural. São Paulo: Loyola, 1994.

LEHER, R.; BARRETO, R. G. Do discurso e das condicionalidades do Banco Mundial, a educação superior "emerge” terciária. Revista Brasileira de Educação, v. 13, n. 39, p. 423-436, set./dez. 2008. Disponível em: <http://www.scielo.br/scielo. php?script=sci_arttext\&pid=S1413-24782008000300002>. Acesso em: 14 fev. 2016.

MANCEBO, D. Crise Político-Econômica no Brasil: Breve análise da educação superior. Educação e Sociedade, Campinas, v. 38, n. 141, p. 875-892, out./ dez. 2017. Disponível em: <http://www.scielo.br/pdf/es/v38n141/1678-4626-eses0101-73302017176927.pdf>. Acesso em: 20 nov. 2017.

MELO, A. A. S. Avaliação Institucional do Ensino Superior: Controle e condução de política educacional, científica e tecnológica. In: SIQUEIRA, A. C.; NEVES, L. M. W. (Org.). Educação Superior: uma reforma em processo. São Paulo: Xamã, 2006. p. $125-145$.

MELO, A. A. S.; SOUSA, F. B. A agenda do mercado e a educação no governo Temer. Germinal: Marxismo e Educação em Debate, Salvador, v. 9, n. 1, p. 25-36, 2017. Disponível em: <https://portalseer.ufba.br/index.php/revistagerminal/article/ view/21619/14336>. Acesso em: 28 set. 2017.

MELLO, A. F.; DIAS, M. A. R. Os reflexos de Bolonha e a América Latina: Problemas e Desafios. Educação e Sociedade, Campinas, v. 32, n. 115, p. 413-435, abr/ jun., 2011. Disponível em: <http://www.scielo.br/scielo.php?script=sci_arttext\&pid $=$ S0101-73302011000200010>. Acesso em: 25 jun. 2016 .

SAVIANI, D. O Plano de Desenvolvimento da Educação: análise do projeto do MEC. Educação e Sociedade, Campinas, n. 100, p. 1231-1255, out. 2007. Disponível em: <http://www.cedes.unicamp.br>. Acesso em: 24 jan. 2016.

SGUISSARDI, V.; SILVA JUNIOR, J. R. Trabalho Intensificado nas Federais:

Pós-Graduação e Produtivismo Acadêmico. São Paulo: Xamã, 2009. 
SHIROMA, E. O.; MORAES, M. C. M.; EVANGELISTA, O. Política Educacional. Rio de Janeiro: DP\&A, 2000.

SILVA JUNIOR, J. R. Reforma do Estado e da Educação no Brasil de FHC. São Paulo, Xamã, 2002.

UGÁ, V. D. A categoria "pobreza" nas formulações de política social do Banco Mundial. Revista de Sociologia Política, Curitiba: UFPR, v. 23, p. 55-62, nov. 2004. Disponível em: <http://www.scielo.br/pdf/rsocp/n23/24621.pdf > . Acesso em: 26 out. 2016.

UNESCO. Declaração Mundial sobre Educação Superior no Século XXI: Visão e Ação. Paris, 1998. Disponível em: <http://www.direitoshumanos.usp.br/index.php/ Direito-a-Educa\%C3\%A7\%C3\%A3o/declaracao-mundial-sobre-educacao-superior-no-seculo-xxi-visao-e-acao.html>. Acesso em: 01 nov. 2017.

Recebido em: 30 de outubro de 2016. Aceito em: 23 de novembro de 2017.

Endereço para correspondência: Rodovia Celso Garcia Cid, s/n, Campus Universitário, 86057-970, Londrina, Paraná, Brasil; elianecleide@gmail.com 
